(c) Н.В. Изможерова, А.А. Попов

ФГБОУ ВО Уральский государственный медицинский университет Минздрава России, Москва, Россия

ЦЕЛЬ: оценка переносимости и эффективности фармакотерапии коморбидной кардиоваскулярной патологии у женщин с постменопаузальным ОП.

MEтоды: в кросс-секционное исследование включены 112 пациенток в возрасте от 49 до 85 лет с постменопаузальным ОП.

РЕЗУЛЬТАТЫ: Показания к назначению ингибиторов АПФ имели 95 человек (84,8\%). С наличием кашля ассоциировались значимо более высокие шансы выявления ИБС и ХСН и тенденция к увеличению частоты множественных остеопоротических переломов. 32 пациенткам с непереносимостью ингибиторов АПФ был назначен валсартан. Через 6 месяцев у 15 женщин были достигнуты целевые цифры АД, у 15 АД стойко снизилось на 30 \% от исходного уровня.

ЗАКЛЮчЕНИЕ: требуется проведение специальных исследований эффективности терапии ССЗ у женщин с посменопаузальным ОП.

КЛЮчЕВЫЕ СЛОВА: Постменопаузальный остеопороз; коморбидность; ингибиторы ангиотензинпревращающего фермента; валсартан;

\title{
PHARMACOTHERAPY OF CARDIOVASCULAR COMORBIDITIES IN OSTEOPOROTIC POSTMENOPAUSAL WOMEN
}

(c) N.V. Izmozherova, A.A. Popov

Ural State Medical University, Moscow, Russia

AIM: to assess tolerability and efficacy of cardiovascular comorbidities pharmacotherapy in osteoporotic postmenopausal women.

METHODS: cross-sectional study included 112 osteoporotic postmenopausal women aged from 49 to 85.

RESULTS: 95 persons (84.8\%) had indications for angiotensine-convertising enzyme inhibitors (ACEI) prescription. Cough was associated with significantly higher odds of coronary heart disease, congestive heart failure and a trend to multiple bone fractures. Valsartan was initiated in 32 coughing patients. Target blood pressure level was reached in 15 women. In 15 cases blood pressure levels decreased by $30 \%$ of baseline level.

CONCLUSION: efficacy of cardiovascular diseases in osteoporotic postmenopausal women treatment needs to be assessed in specially designed clinical trials.

KEYWORDS: Postmenopausal osteoporosis; comorbidity; angiotensin-converting enzyme inhibitors; valsartan;

\section{ОБОСНОВАНИЕ}

Развитие постменопаузального остеопороза (ОП) и сердечно-сосудистых заболеваний (СС3) после наступления менопаузы связывают с дефицитом эстрогенов [1-3]. Помимо менопаузы, ОП и ССЗ имеют ряд общих факторов риска: курение, недостаточную физическую активность, сахарный диабет, заболевания щитовидной железы [1-4].

Ранее было показано, что выраженность и распространенность атеросклеротического процесса у лиц с низкими значениями минеральной плотности кости (МПК) значимо выше по сравнению с лицами, имеющими нормальную МПК $[4,5]$. Одним из важнейших факторов риска атеросклероза, нуждающимся в фармакологической коррекции, является артериальная гипертензия (АГ) [6]. Общие механизмы формирования ССЗ и ОП изучены недостаточно, но известно, что накопление внутриклеточного кальция стимулирует клеточную пролиферацию, ускоряет развитие структурно-функциональных изменений сосудистой стенки $[3,5]$. Атеросклеротическое поражение эндотелия закономерно завершается образованием кальцификата, состоящего из тех же компонентов, что и нормальная кость, солей кальция и фосфата, связанных с гидроксиапатитом. Обнаружена повышенная экспрессия костноформирующих факторов, таких как коллаген, остеокальцин, остеопонтин в атеросклеротической бляшке человека. В целом, взаимодействие эндотелия и мезенхимальных клеток, приводящее к сосудистой кальцификации, сходно с клеточными взаимодействиями, лежащими в основе остеогенеза эмбриональной костной ткани $[2,3]$.

В последнее время были получены данные об увеличении частоты ОП у перенесших инфаркт миокарда [6], 
Таблица 1. Частота сердечно-сосудистых заболеваний и стойкой утраты трудоспособности при наличии постменопаузального остеопороза

\begin{tabular}{lc}
\hline Заболевание & Частота \\
\hline АГ (вне зависимости от степени) & $91(81,3 \%)$ \\
АГ 1 степени & $11(9,8 \%)$ \\
АГ 2 степени & $30(26,8 \%)$ \\
АГ З степени & $50(44,6 \%)$ \\
ИБС: стенокардия напряжения & $40(35,7 \%)$ \\
Инфаркт миокарда в анамнезе & $9(8,0 \%)$ \\
ОНМК в анамнезе & $9(8,0 \%)$
\end{tabular}

ХСН (вне зависимости от функционального класса) 57 (50,9\%)

$\mathrm{XCH} 1$ ф.K.

XCH 2 ф.K.

XCH 3 ф.K.

XCH 4 ф.K.

Стойкая утрата трудоспособности

$58(51,8 \%)$

что также может рассматриваться как доказательство тесной патогенетической взаимосвязи между ССЗ и ОП [3].

\section{ЦЕЛЬ}

Оценка переносимости и эффективности фармакотерапии коморбидной кардиоваскулярной патологии у женщин с постменопаузальным ОП.

\section{МЕТОДЫ}

В проспективное когортное исследование включены 112 пациенток в возрасте от 49 до 85 лет с постменопаузальным ОП, диагностированным на основании низких (Т критерий $\leq-2,5$ стандартных отклонения) значений минеральной плотности поясничного отдела позвоночника и/или проксимального отдела бедра, полученных при двухэнергетической рентгеновской абсорбциометрии на аппарате «Hologic Discovery W QDR» и наличию в анамнезе, как минимум, одного перелома тела позвонка или дистального отдела предплечья, развившегося при минимальной травме [1].

Артериальную гипертензию (АГ) диагностировали согласно рекомендациям Европейского общества кардиологов 2013 года [7]. Хроническая сердечная недостаточность (XCH) диагностировалась на основании «Национальных рекомендаций по диагностике и лечению ХСН» 2013 года [8]. Перенесенные инфаркты миокарда (ИМ) и острые нарушения мозгового кровообращения (ОНМК) регистрировали на основании выписных документов. Диагностику нарушений углеводного обмена проводили по результатам перорального двухчасового тест толерантности к глюкозе (ТТГ). [9]. Критериями исключения были прием глюкокортикоидов и наличие тиреотоксикоза в анамнезе. Критерием эффективности антигипертнехзивной терапии считали достижение целевых уровней артериального давления (АД) и уменьщение функционального класса ХСН [7, 8]

Для оценки значимости различий частот в группах использовали критерий $x^{2}$. Отношение шансов рассчитывали с помощью программного продукта «Epicalc 2000, v.1.02».

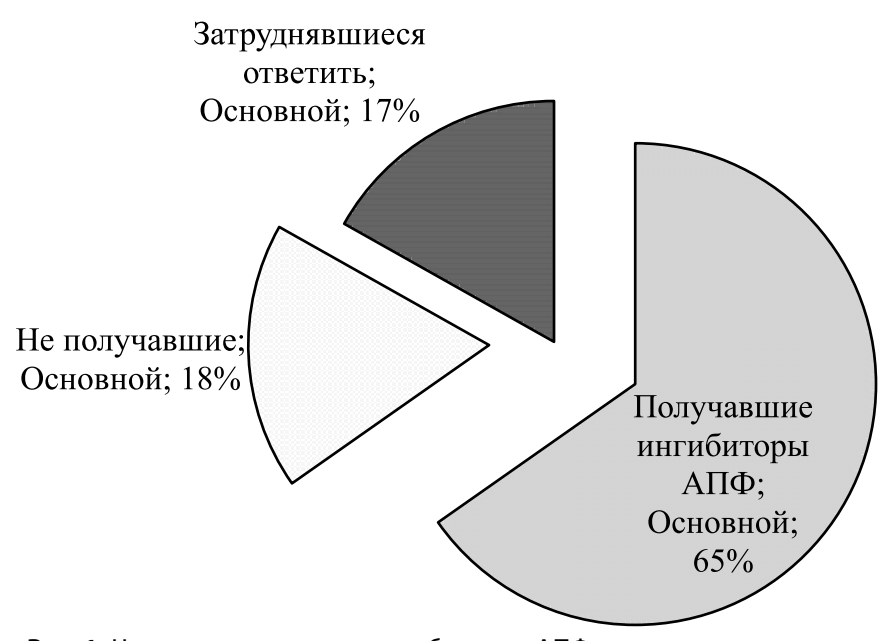

Рис. 1. Частота применения ингибиторов АПФ у женщин с постменопаузальным остеопорозом.

Проведение исследования одобрено Этическим комитетом МБУ ЦГКБ №6 г. Екатеринбурга.

\section{РЕЗУЛЬТАТЫ}

Более 80\% обследованных страдали АГ, причем доминировала 3 степень, частота которой достигла 44,6\%. Кроме того, 35,7 \% пациенток страдали ИБС, причем 8\% из них перенесли инфаркт миокарда. Частота ОНМК также составила 8\% (таб. 1). У 50\% имелись клинические проявления ХСН, главным образом, 2 и 3 функционального класса. Более 50 \% обследованных имели стойкую утрату трудоспособности.

Показания к назначению ингибиторов ангиотензин-превращающего фермента имели 95 человек (84,8\%). Частота применения препаратов этой группы представлена на рис. 1.

Среди 62, получавших ингибиторы АПФ, 32 женщины предъявляли жалобы на наличие кашля, который стал поводом для отмены препарата [10]. Медиана возраста женщин, имевших кашель на ингибиторы АПФ, составила 66,5 (63,0-74,0), переносивших ингибиторы АПФ $66,0(62,0-71,5)$ года. Следует отметить, что ни в одном случае при наличии кашля не были достигнуты целевые цифры АД и сохранялись явления ХСН. Наиболее часто назначаемым препаратом был эналаприл, его получали 48 пациенток, 8 - лизиноприл, 4 - периндоприл. Страдавшие от кашля получали значимо более высокие дозы препарата (в пересчете на эналаприл) 20,0 (10,0-20,0) мг в сравнении с женщинами, не испытывавшими побочных эффектов - 10,0 (10,0-20,0) мг, p=0,035. По частоте приема $\beta$-адреноблокаторов $\left(x^{2}=0,029, p=0,866\right)$ и статинов $\left(x^{2}=0,006, p=0,939\right)$ группы не различались.

Появление кашля при применении ингибиторов АПФ ассоциировалось со значимо более высокими шансами выявления ИБС и ХСН. В свою очередь, развитие ИБС и ХСН обусловливало назначение более высоких доз антигипертензивных препаратов. С другой стороны, выявлена тенденция к увеличению частоты ранее перенесенных множественных остеопоротических переломов у пациенток, жаловавшихся на появление кашля при приёме ингибиторов АПФ (таб. 2).

С учётом непереносимости ингибиторов АПФ 32 пациенткам был назначен блокатор рецепторов ангиотензина II валсартан (Диован, Новартис) в дозе 80-320 мг в сутки. 
Таблица 1. Шансы развития сердечно-сосудистых заболеваний, переломов и стойкой утраты трудоспособности при наличии кашля во время применения ингибиторов АПФ

\begin{tabular}{|c|c|c|c|}
\hline \multirow{2}{*}{ Заболевание } & \multicolumn{2}{|c|}{$\begin{array}{c}\text { Переноси- } \\
\text { мость ИАПФ }\end{array}$} & \multirow{2}{*}{ ОШ } \\
\hline & Кашель & $\begin{array}{c}\text { Нет } \\
\text { кашля }\end{array}$ & \\
\hline ИБС & 24 & 9 & $\begin{array}{c}7,00 \\
(2,29-21,41)\end{array}$ \\
\hline $\mathrm{XCH}$ & 28 & 14 & $\begin{array}{c}8,00 \\
(2,25-28,48)\end{array}$ \\
\hline ИМ+OHМК (в анамнезе) & 9 & 5 & $\begin{array}{c}1,97 \\
(0,57-6,70)\end{array}$ \\
\hline $\begin{array}{l}\text { Стойкая утрата } \\
\text { трудоспособности }\end{array}$ & 26 & 19 & $\begin{array}{c}2,51 \\
(0,79-7,98)\end{array}$ \\
\hline Множественные переломы & 9 & 3 & $\begin{array}{c}3,52 \\
(0,85-14,57)\end{array}$ \\
\hline
\end{tabular}

Обеспечение лекарственным препаратом осуществлялось за счёт средств пациенток, женщины, имевшие группу инвалидности, получали препарат по федеральным программам лекарственного обеспечения. Выбор препарата обусловлен зарегистрированным показанием «хроническая сердечная недостаточность».

На рис. 2 представлена динамика достижения целевых цифр АД в группе женщин, не переносивших ингибиторы АПФ. Через 3 месяца лечения значимое снижение АД наблюдалось у 28 пациенток, а через 6 месяцев у 15 женщин были достигнуты целевые цифры АД, в 15 случаях АД стойко снизилось на 30 \% от исходного уровня (критерий Мак Нимара, $\mathrm{P}<0,001)$.

Улучшение функционального класса ХСН наблюдалось у 10 пациенток из 28 после трех месяцев лечения, через шесть месяцев лечения доля таких женщин составила более 50\% (критерий Мак Нимара, Р <0,001, (рис. 3)).

\section{ОБСУЖДЕНИЕ}

ОП признан независимым фактором риска СС3 $[3,6,11]$. В исследовании, охватившем 9700 женщин в возрасте старше 65 лет, снижение МПК на одно стандартное отклонение от нормы сопровождалось увеличением риска преждевременной смерти от СС3 на 40\% в течение последующих 2 лет [11]. Частота фатального геморрагического или ишемического инсульта у пожилых женщин возрастала на 60\% при снижении МПК. Эта связь не теряла своей силы и ста-

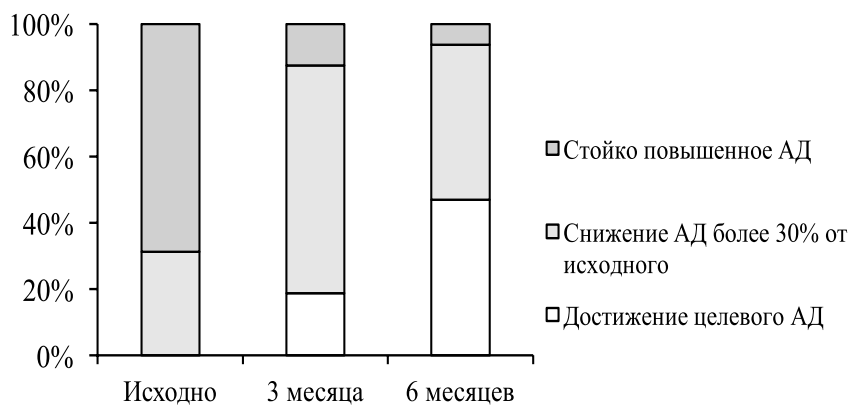

Критерий МакНимара, $\mathbf{p}<0,001$

Рис. 2. Динамика достижения целевых цифр АД на фоне применения валсартана: Критерий МакНимара, $\mathrm{p}<0,001$. тистической значимости и при использовании мультифакторной модели, включавшей известные предикторы смерти (АГ, сахарный диабет, табакокурение, ожирение). Снижение МПК ассоциировалось с риском развития инсульта в большей степени, чем повышение АД [11]. Таким образом, пациенты с остеопорозом нуждаются в профилактике сосудистых событий в большей степени, чем их ровесники с сохраненной МПК [3].

Для понимания причин и механизмов выявленных зависимостей в кросс-секционном исследовании 2726 женщин в постменопаузе и 2543 мужчин в возрасте 55-74 лет (Тромсё, Норвегия) изучалось состояние сонных артерий и минеральная плотность поясничных позвонков. После уравнивания по возрасту, полу и кардиоваскулярным факторам риска наличие тяжелого поражения сонных артерий значимо коррелировало с низкой костной массой. Относительный риск поражения сонных артерий у лиц с наиболее высокой костной массой значимо снижался и составил 0.51 (0,31-0.83), т.е. сохраненная МПК отражает лучшее состояние здоровья пациента в целом [4]. В связи с этим, в проспективном когортном исследовании оценили взаимосвязь кардиоваскулярного риска, переломов и рака молочной железы. Показано значимое увеличение частоты кардиоваскулярных событий и рака молочной железы у женщин до 65 лет с предшествовавшими переломами позвонков. После 65 лет риск любого кардиоваскулярного события был в 3,6 раза выше вне зависимости от наличия переломов [11]. Однако в другом крупном исследовании было продемонстрировано, что смертность была ниже у замужних женщин с остеопорозом при высоком социальном статусе [12].

Развитие ОП и ССЗ также объединяет неадекватная хроническая активация ренин-ангиотензин-альдостероновой и симпатоадреналовой систем, а также эндотелина и вазопрессина [13]. Противостоят им вазодилатирующие, диуретические и антипролиферативные факторы - оксид азота, брадикинин, простациклин и др. Повышение активности АПФ, расположенного на поверхности эндотелиальных клеток, приводит к снижению синтеза оксида азота и повышению тонуса гладкомышечных клеток. Последствиями такого дисбаланса являются усиление процессов сосудистого ремоделирования, воспалительных реакций в сосудистой стенке и облегчение разрыва бляшки с последующим тромбозом [14].

На остеокластах обнаружены высокоспецифичные рецепторы ангиотензина II, стимуляция которых приводит к ускоренной костной резорбции и включению механизмов вазоконстрикции [14]. Таким образом, существование общих медиаторов патологии костной и сердечно-сосудистой системы можно считать частично доказанным [3].

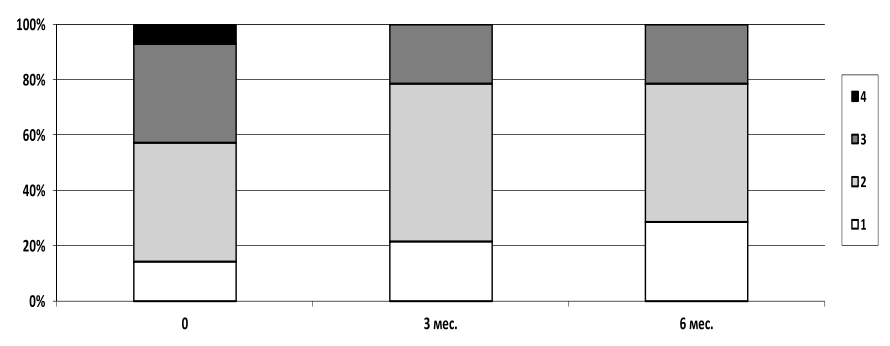

Критерий МакНимара, $\mathrm{p}<0,001$

Рис. 3. Динамика функциональных классов хронической сердечной недостаточности: Критерий МакНимара, $p<0,001$. 
С этой позиции выявленная непереносимость ингибиторов АПФ у женщин с остеопеническим синдромом также заслуживает внимания.

Данные об эффективности различных групп препаратов, применяемых для лечения АГ и ХCH у женщин, весьма неоднозначны [15]. Хотя ингибиторы АПФ признаны стандартом терапии XCH, в исследовании CONSENSUS (COoprative North Scandinavian ENalapril Survival Study) смертность у женщин снизилась только на 6\% по сравнению с 51\% у мужчин [16]. Лишь рамиприл продемонстрировал снижение смертности у женщин после инфаркта миокарда на 32\% [17]. В других крупных исследованиях также не получено данных об эффективности ИАПФ у женщин $[13,15,16]$. Поскольку число участниц в этих исследованиях было не велико, не ясно, связано ли такое различие с малочисленностью включенных в исследование пациенток или с наличием половых различий в реализации эффекта ингибиторов АПФ [13].

Вероятно, среди пациентов с тяжелой комбинированной патологией, нуждающихся в получении максимальных доз ИАПФ, частота кашля может существенно превышать таковую в общей популяции. Данные о частоте кашля при применении ИАПФ существенно варьируют: средняя частота составляет 15\% (от 5 до 35\%), что может быть связано с различным контингентом пациентов, показаниями к применению и используемыми дозами препаратов $[17,18]$. В ряде исследований было показано, что прием $\beta$-адреноблокаторов и иАПФ ассоциировался с более высокой МПК, причем этот феномен более типичен для женщин, чем для мужчин $[17,19,20]$. Прирост МПК на фоне терапии, вероятно, связан с опосредованным влиянием на костный метаболизм в результате регуляции кровотока в капиллярах костных каналов, так и прямым воздействием на рецепторы остеобластов и уменьшение продукции ими медиаторов, стимулирующих костную резорбцию $[18,19]$.

В обследованной группе практически все пациентки имели ХСН с сохраненной фракцией выброса, развившуюся на фоне тяжелой АГ. В связи с чем блокаторы рецепторов ангиотензина II могут рассматриваться как препараты выбора в ситуации обсуждаемой коморбидности, учиты- вая их лучшую переносимость [8]. Ранее при сравнительном анализе влияния ингибиторов АПФ и блокаторов рецепторов ангиотензина II на частоту остеопоретических переломов после учета доз принимаемых препаратов различий по влиянию на клинически значимые выявлено не было [20].

Таким образом, частота перенесенных сердечно-сосудистых событий и, следовательно, актуальность эффективной медикаментозной терапии у женщин с тяжелым постменопаузальным остеопорозом превышает таковые в общей популяции, а переносимость ингибиторов АПФ и достижение клинически значимых эффектов требует бо́льших усилий врача и пациентки. В настоящей работе мы не оценивали влияние длительной терапии иАПФ или блокаторов рецепторов ангиотензина ॥ на МПК. Для улучшения результатов терапии СС3 у женщин с посменопаузальным ОП требуется проведение специальных исследований, в процессе проведения которых будут учтены физиологические особенности и наличие сочетанной соматической патологии.

\section{Выводы}

1. Пациентки с постменопаузальным остеопорозом имеют высокую частоту сердечно-сосудистых заболеваний: АГ, ИБС и ХСН.

2. Прием пациентками с остеопорозом ингибиторов АПФ сопровождается развитием сухого кашля более чем в 50\% случаев.

3. Назначение валсартана в средних терапевтических дозах позволило достичь целевых цифр АД и уменьшить клинические проявления ХСН.

4. Для выработки тактики ведения женщин в постменопаузе с коморбидной патологией необходимо проведение специальных исследований.

\section{ДОПОЛНИТЕЛЬНАЯ ИНФОРМАЦИЯ}

Конфликт интересов. Авторы декларируют отсутствие явных и потенциальных конфликтов интересов, связанных с публикацией настоящей статьи.

\section{СПИСОК ЛИТЕРАТУРЫ | REFERENCES}

1. Лесняк О.М., Алексеева Л.И., Баранова И.А., и др.; Российская ассоциация по остеопорозу. Клинические рекомендации по профилактике и ведению больных с остеопорозом. Издание 2-ое, дополненное. - Ярославль: Литера, 2016. [Lesnyak OM, Alekseeva LI, Baranova IA et al.; Rossiyskaya assotsiatsiya po osteoporozu. Klinicheskie rekomendatsii po profilaktike i vedeniyu bol'nykh s osteoporozom. Second edition. Yaroslavl: Litera; 2016 (In Russ.)].

2. Скрипникова И.А., Оганов Р.Г. Остеопороз и сердечно-сосудистые заболевания (ССЗ) обусловленные атеросклерозом (AC) у женщин постменопаузального периода: общность поведенческих и социальных факторов риска // Остеопороз и остеопатии. 2009. - T. 12. - №2. - C. 5-9. [Skripnikova IA, Oganov RG. Osteoporoz i serdechno-sosudistye zabolevaniya (SSZ) obuslovlennye aterosklerozom (AS) u zhenshchin postmenopauzal'nogo perioda:obshchnost' povedencheskikh i sotsial'nykh faktorov riska. Osteoporosis and Bone Diseases. 2009;12(2):5-9. (In Russ.)] doi: 10.14341/osteo200925-9

3. den Uyl D, Nurmohamed MT, van Tuyl LHD, et al. (Sub)clinical cardiovascular disease is associated with increased bone loss and fracture risk; a systematic review of the association between cardiovascular disease and osteoporosis. Arthritis research \& therapy 2011;13(1):R5. doi: 10.1186/ar3224
4. Jorgensen L. Low Bone Mineral Density Is Related to Echogenic Carotid Artery Plaques: A Population-based Study. American journal of epidemiology. 2004;160(6):549-556. doi: 10.1093/aje/kwh252

5. Майчук, Е.Ю., Митрохина, Т.В., Воеводина, И.В. и др. Сопоставление уровней маркеров атеросклероза и факторов риска сердечно-сосудистых заболеваний с минеральной плотностью кости у женщин применопаузального периода и раннего течения естественной постменопаузы. // Проблемы женского здоровья. 2016. - T. 11. - №. 3. - C. 35-44. [Maichuk EY, Mitrokhina TV, Voevodina IV. Comparison of the level of markers of atherosclerosis and risk factors of cardiovascular disease with mineral density of bone in women of perimenopausal period and the early flow of natural menopause. Problems of women health. 2016;11(3):35-44. (In Russ)].

6. Magnus JH, Broussard DL. Relationship between bone mineral density and myocardial infarction in US adults. Osteoporos Int. 2005;16(12):2053-2062. doi: 10.1007/s00198-005-1999-9

7. Perk J, De Backer G, Gohlke H, et al. European Guidelines on cardiovascular disease prevention in clinical practice (version 2012): The Fifth Joint Task Force of the European Society of Cardiology and Other Societies on Cardiovascular Disease Prevention in Clinical Practice (constituted by representatives of nine societies and by invited 
experts) * Developed with the special contribution of the European Association for Cardiovascular Prevention \& Rehabilitation (EACPR). Eur Heart J. 2012;33(13):1635-1701. doi: 10.1093/eurheartj/ehs092

8. Мареев В.Ю., Агеев Ф.Т., Арутюнов Г.П. и др. Национальные рекомендации ОССН, РКО и РНМОТ по диагностике и лечению ХСН (четвертый пересмотр). // Журнал сердечная недостаточность. - 2013. - Т. 14. - №. 7. - С. 379-472. [Mareev VYu, Ageev FT, Arutyunov GP et al. SEHF, RSC AND RSMSIM National guidelines on CHF diagnostics and treatment (fourth revision). Heart Failure Journal. 2013;14(7):379-472 (In Russ.)] doi: 10.18087/rhf.2013.7.1860

9. Дедов И.И., Шестакова М.В., Галстян Г.Р., и др. Алгоритмы специализированной медицинской помощи больным сахарным диабетом. Под редакцией И.И. Дедова, М.В. Шестаковой (7-й выпуск) // Сахарный диабет. - 2015. - T. 18. - №1S. - C. 1-112. [Dedov II, Shestakova MV, Galstyan GR, et al. Standards of specialized diabetes care. Edited by Dedov II, Shestakova MV (7-th edition). Diabetes mellitus. 2015;18(1S):1-112. (in Russ.)] doi: 10.14341/DM20151S

10. Dicpinigaitis PV. Angiotensin-Converting Enzyme Inhibitor-Induced Cough. Chest. 2006;129(1):169S-173S. doi: 10.1378/chest.129.1_suppl.169S

11. Silverman SL, Delmas PD, Kulkarni PM, et al. Comparison of Fracture, Cardiovascular Event, and Breast Cancer Rates at 3 Years in Postmenopausal Women with Osteoporosis. J Am Geriatr Soc. 2004;52(9):1543-1548. doi: 10.1111/j.1532-5415.2004.52420.x

12. Rutledge T, Matthews K, Lui L-Y, et al. Social Networks and Marital Status Predict Mortality in Older Women. Psychosom Med. 2003;65(4):688-694. doi: 10.1097/01.psy.0000041470.25130.6c

13. Butt DA, Mamdani M, Gomes T, et al. Risk of Osteoporotic Fractures With Angiotensin II Receptor Blockers Versus Angiotensin-Converting Enzyme Inhibitors in Hypertensive Community-Dwelling Elderly. J Bone Miner Res. 2014;29(11):2483-2488. doi: 10.1002/jbmr.2271
14. Aoki M, Kawahata H, Sotobayashi D, et al. Effect of angiotensin II receptor blocker, olmesartan, on turnover of bone metabolism in bedridden elderly hypertensive women with disuse syndrome. Geriatrics \& Gerontology International. 2015;15(8):1064-1072. doi: 10.1111 /ggi.12406

15. White HD. Mortality and Morbidity Remain High Despite Captopri and/or Valsartan Therapy in Elderly Patients With Left Ventricular Systolic Dysfunction, Heart Failure, or Both After Acute Myocardial Infarction: Results From the Valsartan in Acute Myocardial Infarction Trial (VALIANT). Circulation. 2005;1 12(22):3391-3399. doi: $10.1161 /$ circulationaha.105.551143

16. Effects of Enalapril on Mortality in Severe Congestive Heart Failure. N Engl J Med. 1987;316(23):1429-1435. doi: 10.1056/nejm198706043162301

17. Shekelle PG, Rich MW, Morton SC, et al. Efficacy of angiotensin-converting enzyme inhibitors and beta-blockers in the management of left ventricular systolic dysfunction according to race, gender, and diabetic status. J Am Coll Cardiol. 2003;41 (9):1529-1538. doi: 10.1016/s0735-1097(03)00262-6

18. Morice AH. Cough * 1: Chronic cough in adults. Thorax. 2003;58(10):901-907. doi: 10.1136/thorax.58.10.901

19. Скрипникова И.А., Собченко К.Е., Абирова Э.С., и др. Изучение плейотропных эффектов в-адреноблокаторов и ингибиторов апф на костную ткань // Остеопороз и остеопатии. - 2014. T. 17. - №1. - C. 3-7. [Skripnikova IA, Sobchenko KE, Abirova ES, et al. Izuchenie pleyotropnykh effektov $\mathrm{v}$-adrenoblokatorov $\mathrm{i}$ ingibitorov APF na kostnuyu tkan'. Osteoporosis and Bone Diseases. 2014;17(1):3-7. (In Russ)] doi: 10.14341/osteo201413-7

20. Lynn H, Kwok T, Wong SYS, et al. Angiotensin converting enzyme inhibitor use is associated with higher bone mineral density in elderly Chinese. Bone. 2006;38(4):584-588. doi: 10.1016/j.bone.2005.09.011

\section{ИНФОРМАЦИЯ ОБ АВТОРАХ [AUTHORS INFO]}

Попов Артем Анатольевич, д.м.Н., профессор, доцент кафедры госпитальной терапии [Artem A. Popov, MD, PhD, professor]; адрес: 620028, г. Екатеринбург, ул. Репина, 3 [address: 3, Repina street, Ekaterinburg, 620028]; телефон: (7-343) 214-86-99; ORCID: http://orcid.org/0000-0001-6216-2468; eLibrary SPIN: 5083-9389; e-mail: art_popov@mail.ru

Изможерова Надежда Владимировна, д.м.н., профессор кафедры внутренних болезней №2 [Nadezhda V. Izmozherova, MD, PhD, professor]; ORCID: https:// orcid.org/0000-0001-7826-9657; eLibrary SPIN: 4738-3269

\section{ЦИТИРОВАТЬ:}

Изможерова Н.В., Попов А.А. Особенности фармакотерапии коморбидных сердечно-сосудистых заболеваний у женщин с постменопаузальным остеопорозом. // Остеопороз и остеопатии. — 2017. — Т. 20. — №1. — C.17-21. doi: 10.14341/osteo2017117-21

\section{TO CITE THIS ARTICLE:}

Izmozherova NV, Popov AA. Pharmacotherapy of cardiovascular comorbidities in osteoporotic postmenopausal women. Osteoporosis and bone diseases. 2017;20(1):17-21. doi: 10.14341/osteo2017117-21 